the brain region in which memories are thought to be consolidated.

These findings echo recent experiments in which human sensory learning improved following exposure to taskrelated cues during sleep, suggesting that such cues might strengthen memories. Nature Neurosci. http://dx.doi. org/10.1038/nn.3203 (2012)

NANOTECHNOLOGY

\section{Bigger rings allow thinner nanotubes}

An ultrathin carbon nanotube that is stable up to temperatures of 1,000 kelvin has been predicted by a team at the Autonomous University of Madrid. The structure resembles a double helix, with alternating single, double and triple carboncarbon bonds.

Eduardo MenéndezProupin and his colleagues simulated the structure and described the spectral signatures that would enable scientists to identify it experimentally. The predicted molecule is just 0.32 nanometres in diameter. Standard nanotubes this thin have never been observed, because the carbon bonds in their six-atom rings have large distortions and become destabilized as the nanotubes get thinner. The carbon rings in the predicted molecule are larger than in standard nanotubes, and the bonds are arranged such that they are less strained.

Phys. Rev. Lett. 109, 105501 (2012)

\section{NEUROSCIENCE}

\section{Social isolation} thins neural sheath

Mice raised in isolation are unsociable and slow to learn complex tasks as adults. Failure to develop normal coatings around neurons during a crucial growth period could explain these deficits.

Gabriel Corfas at Boston
Children's Hospital in

Massachusetts and his colleagues found that mice isolated between 21 and 35 days old were particularly vulnerable to lasting effects. In these mice, oligodendrocytes - cells that produce the fatty layers which sheath neurons to facilitate electrical signalling - made abnormally thin sheaths in the prefrontal cortex, an area linked to sociability and memory.

In the same brain area, isolated mice showed reduced levels of NRG1, a protein that has a role in oligodendrocyte development. Mice engineered to lack an NRG1 receptor in oligodendrocytes mimicked the negative effects of isolation, suggesting that social experience might affect neural development through the NRG1 signalling pathway. Science 337, 1357-1360 (2012)

\section{PLANETARY SCIENCE}

\section{Volcanic signs in Martian clays}

Clay minerals on the surface of Mars (pictured) could be signs of previous volcanic activity rather than an indication that the planet had a warm and wet climate in the past, as has been assumed.

Clays can form when igneous rock is altered by water present at the surface or underground. But Alain Meunier at the University of Poitiers in France and his colleagues suggest that the Martian clays could have precipitated directly out of a water-rich magma, which filled voids in the igneous rock as it cooled. When the researchers analysed rocks from terrestrial lavas from a French Polynesian atoll, they found similar spectral signatures to those of the Martian clays.

The authors' suggestion soon to be investigated by the Mars rover Curiosity - is that the planet's early climate was volcanic, but not necessarily wet.

Nature Geosci. http://dx.doi. org/10.1038/ngeo1572 (2012)

COMMUNITY CHOICE

The most viewed papers in science

\title{
GEOLOGY
}

\section{One million years of rubbing rocks}

HIGHLY READ
on geology.
gsapubs.org
in August

Jay Quade at the University of Arizona in Tucson and his colleagues analysed the patterns of erosion shown by the boulders. The researchers determined that the rocks' smooth sides, and depressions in the sediment around them, could be best explained by rubbing and rocking motions experienced during earthquakes. In February 2010, two members of the team were present when an earthquake with a magnitude of 5.2 struck about 100 kilometres from their location, enabling them to observe the rocks rubbing against each other for about a minute.

Earthquakes of a similar or larger magnitude occur roughly once every four months, and the authors calculate that the boulders could have experienced 40,000-70,000 hours of rubbing over the past 1.3 million years.

Geology 40, 851-854 (2012)

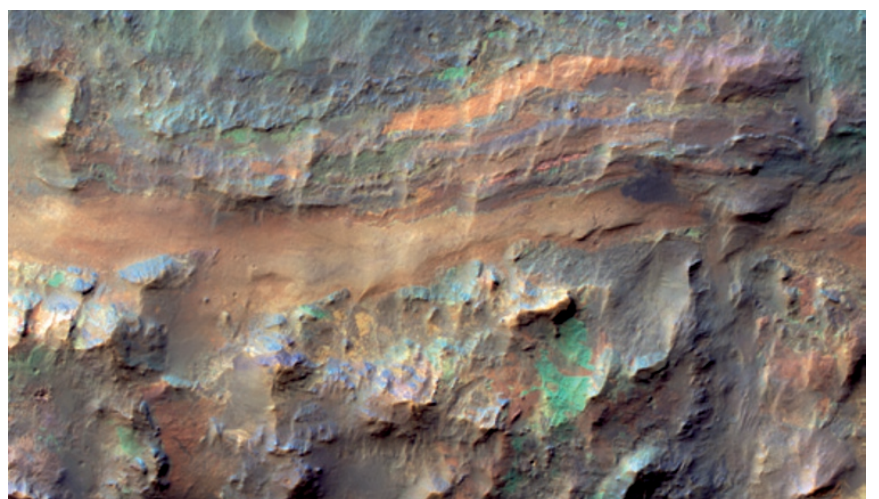

ORGANIC CHEMISTRY

\section{Tagging molecules with fluorine}

Attaching fluorine atoms to organic molecules is important in, for example, tweaking the properties of a drug candidate. John Groves at Princeton University in New Jersey and his colleagues have now discovered a way to substitute fluorine atoms at previously inaccessible positions in a molecule: carbon-hydrogen bonds, which are notoriously unreactive.

The researchers used a manganese porphyrin catalyst to assist the reaction, which they say requires only simple apparatus and mild conditions. They were able to fluorinate simple hydrocarbons and even complex steroid molecules with yields of up to $60 \%$.

The technique could be used to incorporate radioactive fluorine into a wide range of biomolecules for imaging.

Science 337, 1322-1325 (2012)

\section{DNATURE.COM}

For the latest research published by Naturevisit:

www.nature.com/latestresearch 